\title{
Pancreatic beta cell protection/regeneration with phytotherapy
}

\author{
Azar Hosseini, Reza Shafiee-Nick, Ahmad Ghorbani" \\ Pharmacological Research Center of Medicinal Plants, School of Medicine, \\ Mashhad University of Medical Sciences, Mashhad, Iran
}

\begin{abstract}
Although currently available drugs are useful in controlling early onset complications of diabetes, serious late onset complications appear in a large number of patients. Considering the physiopathology of diabetes, preventing beta cell degeneration and stimulating the endogenous regeneration of islets will be essential approaches for the treatment of insulin-dependent diabetes mellitus. The current review focused on phytochemicals, the antidiabetic effect of which has been proved by pancreatic beta cell protection/regeneration. Among the hundreds of plants that have been investigated for diabetes, a small fraction has shown the regenerative property and was described in this paper. Processes of pancreatic beta cell degeneration and regeneration were described. Also, the proposed mechanisms for the protective/ regenerative effects of such phytochemicals and their potential side effects were discussed.
\end{abstract}

Uniterms: Diabetes mellitus/treatment. Diabetes mellitus/phytotherapy. Phytotherapy/Diabetes mellitus. Islets/endogenous regeneration. Beta cells/protection. Beta cells/regeneration. Pancreas. Medicinal plants/regenerative properties.

\begin{abstract}
Embora medicamentos disponíveis atualmente sejam úteis no controle de complicações da Diabetes, complicações aparecem em grande número de pacientes. Considerando-se a fisiopatologia do Diabetes, a prevenção da degeneração de células beta e o estímulo da regeneração endógena de ilhotas será abordagem essencial para o tratamento de diabetes mellitus insulino-dependente. A presente revisão aborda compostos fitoquímicos, cujo efeito é provado na proteção/regeneração de células beta de pâncreas. Entre centenas de plantas que têm sido investigadas para o diabetes, pequena fração tem mostrado propriedade regenerativa, que será descrita neste trabalho. Os processos de degeneração e de regeneração das células beta do pâncrease são descritos. Além disso, mecanismos propostos para efeitos de proteção e regeneração desses compostos fitoquímicos e seus possíveis efeitos colaterais também serão discutidos neste trabalho.
\end{abstract}

Unitermos: Diabetes mellitus/tratamento. Diabetes mellitus/fitoterapia. Fitoterapia/Diabetes mellitus. Ilhotas/regeneração endógena. Células beta/proteção. Células beta/regeneração. Pâncreas. Plantas medicinais/propriedades regenerativas.

\section{INTRODUCTION}

Diabetes mellitus is still one of the most important causes of death and disability in both developed and developing countries. According to the report by World Health Organization (WHO, 2015), 9\% of adults in the world suffer from diabetes and this disease will be the $7^{\text {th }}$ leading cause of death in 2030 . Generally, diabetes is classified into two main types: type 1 diabetes (T1D) and

*Correspondence: Ahmad Ghorbani. Pharmacological Research Center of Medicinal Plants, School of Medicine, Mashhad University of Medical Sciences, Mashhad, Iran. E-mail: ghorbania@mums.ac.ir type 2 diabetes (T2D), which were previously known as insulin- and non-insulin-dependent diabetes, respectively. T1D results from pancreatic beta cell degeneration and is characterized by lack of insulin production, while patients with T2D show a state of insulin resistance and usually relative insulin deficiency. Over time, diabetic patients with poor management undergo micro- and macro-vascular complications including nephropathy, retinopathy, neuropathy, and cardiovascular diseases (Deshpande, Harris-hayes, Schootman, 2008).

At present, only insulin and oral antihyperglycemic drugs are available for T1D management (Lorenzati et al., 2010). Although the currently available drugs 
are useful in controlling early onset complications of diabetes, serious late onset complications appear in a large number of patients (Tzoulaki et al., 2009). Considering the physiopathology of diabetes, preventing beta cell degeneration and stimulating the endogenous regeneration of islets will be essential approaches in treatment of diabetes.

Phytochemicals have always been an important source of remedies for human health problems. Numerous experimental and clinical studies have documented beneficial effects of phytotherapy for managing diabetes (Ghorbani, 2013a,b). Antidiabetic effect of phytochemicals is mediated through different mechanisms such as decreasing glucose absorption from intestine, inhibiting glucose production in the liver, increasing glucose uptake by tissues, enhancing insulin secretion from beta cells, and/or increasing pancreatic tissue regeneration (Asgary et al., 2008; Kamyab et al., 2010; Jelodar, Mohsen, Shahram, 2007; Shafiee-Nick et al., 2011; Shafiee-Nick et al., 2012a). The current review focused on phytochemicals, the antidiabetic action of which has been proved, at least in part, by pancreatic beta cell protection or regeneration (Table I).

\section{Method of literature review}

Review of the related literature was carried out in the databases of Google Scholar, Medline, and Scopus. The search terms included diabetes, islets, pancreas, plant, herb, and regeneration. Cross references of the related articles were also retrieved. Papers were included if they reported the effect of a plant or phytochemical agent on histopathological features of islets of Langerhans in diabetic animals. Two authors (A.G. and A.H.) independently searched the databases and extracted data from each article.

\section{Pancreatic beta cell degeneration/regeneration}

T1D is primarily considered as an autoimmune disease resulting from the reaction of immune effector cells with endogenous beta cell antigens. Gradual invasion of T-cells, macrophages, and the released cytokines and oxidative radicals lead to insulitis. The proinflammatory cytokines, especially tumor necrosis factor alpha, interferon gamma, and interleukine-1 beta activate intracellular pathways and lead to beta cell dysfunction, apoptosis, and necrosis. Because of poor intracellular antioxidant capacity, beta cells are vulnerable to oxidative stress. Therefore, oxidative molecules are important mediators of beta cell damage induced by both T1D insulitis and T2D glucotoxicity (Sharma et al., 2009).

Many of the advances in the pathogenesis of T1D have emerged from animal studies. Streptozotocin (STZ) or alloxan-induced diabetic rat or mouse is the most currently used animal model for diabetes. A single intraperitoneal or intravenous injection of STZ is well reported to induce insulin-dependent diabetes in rats (Ghorbani et al., 2010; Ghorbani et al., 2013; Shafiee-Nick et al., 2012b). The histologic feature of islets from the pancreas of diabetic animals is characterized by a severe decrease in the number of islets, inflammation, vacuolation of the islets, and degranulation of the beta cells (Adeyemi et al., 2008; Aralelimath, Bhise, 2012). In addition, regular arrangement of alpha and beta cells is disturbed and clumping of beta cells, pyknosis, and necrosis are seen in the islets (Singh et al., 2008).

The subject of pancreatic beta cell regeneration is one of the most controversial topics of T1D research and treatment. It is believed that beta cell can regenerate through the replication of pre-existing beta cells or neogenesis from stem cells and progenitor cells inside or outside the islets (Bouwens, Rooman, 2005). Meier et al. (2006) showed a direct piece of evidence for beta cell regeneration through beta cell replication in T1D patients. Neogenesis can be originated from different cell types within pancreas: alpha cells, delta cells, duct epithelium, acinar cells, and centroacinar cells. However, this process depends on extra-pancreatic activators including hormones, growth factors, and others (Bouwens, Rooman, 2005). In adults, turnover of beta cells is slow and reduces with increasing age. However, during body growth and after injury, beta cells can replicate to maintain glucose homeostasis (Avolio et al., 2013). Several approaches are currently being investigated to differentiate stem/progenitor cells into beta cells; but, none has been approved for use in diabetic patients yet. Therefore, further works on this issue are warranted.

\section{Phytochemicals with protective/regenerative effects}

\section{Allium sativum}

Garlic (Allium sativum) has been long used as an herbal remedy in treating different diseases because of its antioxidant, antihypertensive, and anticancer effects (Afshari et al., 2006; Ashraf et al., 2013; Benkeblia, 2005; Hajzadeh et al., 2006). It is also one of the best-researched medicinal plants in terms of managing diabetes. Clinical trials have shown that the consumption of garlic decreases 
TABLE I - Phytochemicals with protective/regenerative effects on pancreatic beta cells.

\begin{tabular}{|c|c|c|c|c|c|}
\hline Plants & Animal model & Treatment & Effects on pancreas & Other effects & Reference \\
\hline Abroma augusta & $\begin{array}{l}\text { ALO-induced } \\
\text { diabetic rabbits }\end{array}$ & $\begin{array}{l}\text { Aqueous extract of } \\
\text { leaves }(2 \mathrm{~mL} / \mathrm{kg} \text {, } \\
\text { twice daily, } \mathrm{PO}) \text { for } \\
21 \text { days }\end{array}$ & $\uparrow$ beta cell number & $\begin{array}{l}\downarrow \text { FBG }, \downarrow \text { blood urea, } \\
\downarrow \text { serum creatinin }\end{array}$ & $\begin{array}{l}\text { Mir, Darzi, Mir, } \\
2013\end{array}$ \\
\hline $\begin{array}{l}\text { Alchornea } \\
\text { cordifolia }\end{array}$ & $\begin{array}{l}\text { ALO-induced } \\
\text { diabetic rabbits }\end{array}$ & $\begin{array}{l}\text { Ethanolic extract of } \\
\text { leaves }(250 \& \\
500 \mathrm{mg} / \mathrm{kg}, \mathrm{PO}) \text { for } \\
28 \text { days }\end{array}$ & $\begin{array}{l}\text { Regeneration of beta } \\
\text { cells (at } 500 \mathrm{mg} / \mathrm{kg} \text { ) }\end{array}$ & - & $\begin{array}{c}\text { Eliakim-Ikechukwu, } \\
\text { Obri, } 2009\end{array}$ \\
\hline \multirow{3}{*}{ Allium sativum } & \multirow{3}{*}{$\begin{array}{l}\text { STZ-induced } \\
\text { diabetic rats }\end{array}$} & $\begin{array}{l}\text { Aqueous extract } \\
(100 \mathrm{mg} / \mathrm{kg} / \text { day }) \text { for } \\
30 \text { days }\end{array}$ & $\uparrow$ islets diameter & $\begin{array}{l}\downarrow \mathrm{FBG}, \uparrow \text { serum } \\
\text { insulin }\end{array}$ & Albajali et al., 2011 \\
\hline & & $\begin{array}{l}\text { Allicin }(8 \& \\
16 \mathrm{mg} / \mathrm{kg}, \mathrm{IP}) \text { for } \\
30 \text { days }\end{array}$ & $\begin{array}{l}\downarrow \text { anti-islet cell } \\
\text { antibodies; } \downarrow \text { beta cell } \\
\text { degeneration }\end{array}$ & $\begin{array}{l}\uparrow \text { serum insulin, } \\
\downarrow \text { FBG, } \downarrow \text { weight lost, }\end{array}$ & Osman et al., 2012 \\
\hline & & $\begin{array}{l}\text { A. sativum oil (10 \& } \\
20 \mathrm{mg} / \mathrm{kg} \text {, IP)for } \\
30 \text { days }\end{array}$ & $\begin{array}{l}\text { Regeneration } \\
\text { of pancreatic islets } \\
\text { (at } 20 \mathrm{mg} / \mathrm{kg})\end{array}$ & $\begin{array}{l}\downarrow \mathrm{FBG}, \uparrow \text { serum } \\
\text { insulin, } \downarrow \text { weight lost }\end{array}$ & $\begin{array}{l}\text { Alashkham et al., } \\
2013\end{array}$ \\
\hline $\begin{array}{l}\text { Amaranthus } \\
\text { caudatus }\end{array}$ & $\begin{array}{l}\text { STZ-induced } \\
\text { diabetic rats }\end{array}$ & $\begin{array}{l}\text { Methanolic extract } \\
\text { of leaves }(200 \& \\
400 \mathrm{mg} / \mathrm{kg}, \mathrm{PO}) \text { for } \\
21 \text { days }\end{array}$ & $\begin{array}{l}\text { Slight regeneration of } \\
\text { beta cells (at } \\
400 \mathrm{mg} / \mathrm{kg} \text { ) }\end{array}$ & $\begin{array}{l}\downarrow \text { FBG }, \downarrow \text { weight lost, } \\
\downarrow \text { serum lipids }\end{array}$ & Girija et al., 2011 \\
\hline $\begin{array}{l}\text { Amaranthus } \\
\text { spinosus }\end{array}$ & $\begin{array}{l}\text { STZ-induced } \\
\text { diabetic rats }\end{array}$ & $\begin{array}{l}\text { Methanolic extract of } \\
\text { leaves }(200 \& \\
400 \mathrm{mg} / \mathrm{kg}, \mathrm{PO}) \\
\text { for } 21 \text { days }\end{array}$ & $\begin{array}{l}\text { Slight regeneration } \\
\text { of beta cells } \\
\text { (at } 400 \mathrm{mg} / \mathrm{kg} \text { ) }\end{array}$ & $\begin{array}{l}\downarrow \text { FBG }, \downarrow \text { weight lost, } \\
\downarrow \text { serum lipids }\end{array}$ & Girija et al., 2011 \\
\hline $\begin{array}{l}\text { Amaranthus } \\
\text { viridis }\end{array}$ & $\begin{array}{l}\text { STZ-induced } \\
\text { diabetic rats }\end{array}$ & $\begin{array}{l}\text { Methanolic extract } \\
\text { of leaves }(200 \& \\
400 \mathrm{mg} / \mathrm{kg}, \mathrm{PO}) \\
\text { for } 21 \text { days }\end{array}$ & $\begin{array}{l}\text { Slight regeneration } \\
\text { of beta cells } \\
\text { (at } 400 \mathrm{mg} / \mathrm{kg} \text { ) }\end{array}$ & $\begin{array}{l}\downarrow \text { FBG }, \downarrow \text { weight lost, } \\
\downarrow \text { serum lipids }\end{array}$ & Girija et al., 2011 \\
\hline $\begin{array}{l}\text { Anacardium } \\
\text { occidentale }\end{array}$ & $\begin{array}{l}\text { STZ-induced } \\
\text { diabetic rats }\end{array}$ & $\begin{array}{l}\text { A. occidentale extract } \\
(300 \& 500 \mathrm{mg} / \mathrm{kg}, \\
\text { twice daily) for } \\
28 \text { days }\end{array}$ & $\begin{array}{l}\text { Regeneration of } \\
\text { pancreatic beta cells }\end{array}$ & $\downarrow F B G$ & $\begin{array}{c}\text { Bassey, Eliakim- } \\
\text { Ikechukw, Ihentuge, } \\
2012\end{array}$ \\
\hline \multirow[b]{2}{*}{$\begin{array}{l}\text { Anastatica } \\
\text { hierochuntica }\end{array}$} & $\begin{array}{l}\text { STZ-induced } \\
\text { diabetic rats }\end{array}$ & $\begin{array}{l}\text { Aqueous extract } \\
(12.5 \mathrm{mg} / \mathrm{rat}, \mathrm{PO}) \\
\text { for } 2 \text { weeks }\end{array}$ & $\uparrow$ beta cell number & $\downarrow$ FBG & $\begin{array}{c}\text { Rahmy, El-Ridi, } \\
2002\end{array}$ \\
\hline & $\begin{array}{l}\text { ALO-induced } \\
\text { diabetic rats }\end{array}$ & $\begin{array}{l}\text { Methanolic extract } \\
(100 \mathrm{mg} / \mathrm{kg}, \mathrm{PO}) \\
\text { for } 4 \text { weeks }\end{array}$ & $\begin{array}{l}\uparrow \text { volume density of } \\
\text { islets, } \uparrow \text { percentage } \\
\text { of beta cells }\end{array}$ & $\begin{array}{l}\downarrow \text { FBG, } \downarrow \text { serum } \\
\text { lipids, } \downarrow \text { weight lost, } \\
\downarrow \text { liver enzymes } \\
\text { activity, } \uparrow \text { antioxidant } \\
\text { enzymes activity }\end{array}$ & $\begin{array}{c}\text { Shaban, Al-Azzawie } \\
\text { Mohamme, } 2011\end{array}$ \\
\hline \multirow{2}{*}{ Annona muricata } & \multirow{2}{*}{$\begin{array}{l}\text { STZ-induced } \\
\text { diabetic rats }\end{array}$} & $\begin{array}{l}\text { Aqueous extract of } \\
\text { leaves }(100 \mathrm{mg} / \mathrm{kg} \text {, } \\
\text { PO) for } 25 \text { days }\end{array}$ & $\uparrow$ beta cell number & $\begin{array}{l}\downarrow \mathrm{FBG}, \uparrow \text { serum } \\
\text { insulin, } \downarrow \text { oxidative } \\
\text { stress indexes in } \\
\text { blood }\end{array}$ & $\begin{array}{l}\text { Adewole, Caxton- } \\
\text { martins, } 2006\end{array}$ \\
\hline & & $\begin{array}{l}\text { Methanolic extract of } \\
\text { leaves }(100 \mathrm{mg} / \mathrm{kg} \text {, } \\
\text { IP) for } 2 \text { weeks }\end{array}$ & 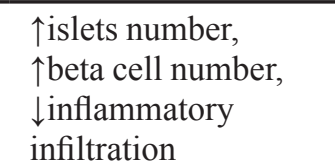 & $\downarrow F B G$ & Adeyemi et al., 2008 \\
\hline
\end{tabular}


TABLE I - Phytochemicals with protective/regenerative effects on pancreatic beta cells. (cont.)

\begin{tabular}{|c|c|c|c|c|c|}
\hline Plants & Animal model & Treatment & Effects on pancreas & Other effects & Reference \\
\hline $\begin{array}{l}\text { Artanema } \\
\text { sesamoides }\end{array}$ & $\begin{array}{l}\text { STZ-induced } \\
\text { diabetic rats }\end{array}$ & $\begin{array}{l}\text { Methanolic extract } \\
\text { of aerial parts }(200 \& \\
400 \mathrm{mg} / \mathrm{kg}, \mathrm{PO}) \text { for } \\
14 \text { days }\end{array}$ & $\begin{array}{l}\downarrow \text { necrosis of islet } \\
\text { cells, } \downarrow \text { degeneration } \\
\text { of the islets }\end{array}$ & $\begin{array}{l}\downarrow \mathrm{FBG}, \downarrow \text { serum lipids, } \\
\downarrow \text { liver enzymes } \\
\text { activity, } \downarrow \text { liver and } \\
\text { kidney damage, } \\
\uparrow \text { antioxidant defense } \\
\text { in liver and kidney }\end{array}$ & Selvan et al., 2008 \\
\hline \multirow{2}{*}{$\begin{array}{l}\text { Azadirachta } \\
\text { indica }\end{array}$} & $\begin{array}{l}\text { ALO-induced } \\
\text { diabetic rats }\end{array}$ & $\begin{array}{l}\text { Alcoholic extract of } \\
\text { leaves }(400 \mathrm{mg} / \mathrm{kg} \text {, } \\
\text { twice daily, PO) for } \\
14 \text { days }\end{array}$ & $\begin{array}{l}\text { Regeneration of new } \\
\text { islets }\end{array}$ & $\downarrow F B G$ & Ebong et al., 2006 \\
\hline & $\begin{array}{l}\text { STZ-induced } \\
\text { diabetic rats }\end{array}$ & $\begin{array}{l}\text { Ethanolic extract of } \\
\text { leaves }(500 \mathrm{mg} / \mathrm{kg} \text {, } \\
\text { twice daily, PO) for } \\
50 \text { days }\end{array}$ & $\begin{array}{l}\uparrow \text { beta cell density; } \\
\downarrow \text { pancreatic lipid } \\
\text { hydroperoxide levels }\end{array}$ & $\downarrow F B G$ & $\begin{array}{l}\text { Akinola, Caxton- } \\
\text { Martins, Dini, } 2010\end{array}$ \\
\hline $\begin{array}{l}\text { Bauhinia } \\
\text { variegata }\end{array}$ & $\begin{array}{l}\text { ALO-induced } \\
\text { diabetic rats }\end{array}$ & $\begin{array}{l}\text { Ethanol extract of } \\
\text { bark }(500 \mathrm{mg} / \mathrm{kg}, \mathrm{PO}) \\
\text { for } 15 \text { days }\end{array}$ & $\begin{array}{l}\text { Restored the cellular } \\
\text { size and number of } \\
\text { islets towards normal }\end{array}$ & $\downarrow \mathrm{FBG}, \downarrow$ serum lipids & Koti et al., 2009 \\
\hline \multirow[b]{2}{*}{ Berberine } & $\begin{array}{l}\text { ALO-induced } \\
\text { diabetic rats }\end{array}$ & $\begin{array}{l}\text { berberine }(100 \& \\
200 \mathrm{mg} / \mathrm{kg}, \mathrm{PO}) \\
\text { for } 21 \text { days }\end{array}$ & $\begin{array}{l}\text { Moderate expansion } \\
\text { of islets, } \downarrow \text { damage } \\
\text { scores }\end{array}$ & $\begin{array}{l}\downarrow F B G, \downarrow \text { serum } \\
\text { lipids, } \downarrow \text { oxidative } \\
\text { stress in the heart }\end{array}$ & Tang et al., 2006 \\
\hline & $\begin{array}{l}\text { STZ- and high } \\
\text { carbohydrate/ } \\
\text { fat diet-induced } \\
\text { diabetic rats }\end{array}$ & $\begin{array}{l}\text { berberine } \\
(75-300 \mathrm{mg} / \mathrm{kg}, \mathrm{PO}) \\
\text { for } 16 \text { weeks }\end{array}$ & $\begin{array}{l}\uparrow \text { beta cells number, } \\
\uparrow \text { insulin expression, } \\
\downarrow \text { oxidative stress } \\
\text { indexes }\end{array}$ & $\uparrow$ serum insulin & Zhou et al., 2009 \\
\hline Cassia alata & $\begin{array}{l}\text { STZ-induced } \\
\text { diabetic rats }\end{array}$ & $\begin{array}{l}\text { Ethanolic extract of } \\
\text { leaves }(500 \mathrm{mg} / \mathrm{kg} \text {, } \\
\text { twice daily, PO) } \\
\text { for } 28 \text { days }\end{array}$ & $\begin{array}{l}\text { Regeneration of beta } \\
\text { cells }\end{array}$ & $\downarrow \mathrm{FBG}$ & $\begin{array}{l}\text { Eliakim-Ikechukwu } \\
\text { et al., } 2013\end{array}$ \\
\hline $\begin{array}{l}\text { Cassia } \\
\text { occidentalis }\end{array}$ & $\begin{array}{l}\text { ALO-induced } \\
\text { diabetic rats }\end{array}$ & $\begin{array}{l}\text { Aqueous extract of } \\
\text { whole plant } \\
(200 \mathrm{mg} / \mathrm{kg}, \mathrm{PO}) \\
\text { for } 21 \text { days }\end{array}$ & $\begin{array}{l}\text { Partial restoration of } \\
\text { cellular population } \\
\text { and size of islet cells }\end{array}$ & $\downarrow$ FBG,$\downarrow$ serum lipids & Verma et al., 2010 \\
\hline Clitoria ternatea & $\begin{array}{l}\text { STZ-induced } \\
\text { diabetic rats }\end{array}$ & $\begin{array}{l}\text { Ethanolic extract } \\
\text { of aerial parts } \\
(200 \mathrm{mg} / \mathrm{kg}, \mathrm{PO}) \\
\text { for } 21 \text { days }\end{array}$ & $\begin{array}{l}\downarrow \text { necrosis of islets, } \\
\downarrow \text { fibrosis of islets, } \\
\text { improvement in beta } \\
\text { cell granulation }\end{array}$ & $\begin{array}{l}\downarrow \text { FBG }, \downarrow \text { weight lost, } \\
\downarrow \text { serum lipids }\end{array}$ & $\begin{array}{l}\text { Verma, Itankar, } \\
\text { Arora, } 2013\end{array}$ \\
\hline \multirow{2}{*}{ Curcumin } & $\begin{array}{l}\text { STZ-induced } \\
\text { diabetic mice }\end{array}$ & $\begin{array}{l}\text { Curcumin } \\
(200 \mathrm{mg} / \mathrm{kg}, \mathrm{IP}) \\
\text { for } 12 \text { weeks } \\
\end{array}$ & $\begin{array}{l}\downarrow \text { lymphocytes } \\
\text { infiltration in the } \\
\text { islets, } \uparrow \text { islets number }\end{array}$ & $\downarrow$ FBG,$\downarrow$ weight loss & $\begin{array}{c}\text { Chanpoo, } \\
\text { Petchpiboonthai, } \\
2010 \\
\end{array}$ \\
\hline & $\begin{array}{l}\text { STZ-induced } \\
\text { diabetic rats }\end{array}$ & $\begin{array}{l}\text { Curcumin derivative } \\
(150 \mathrm{mg} / \mathrm{kg}, \mathrm{PO}) \\
\text { for } 40 \text { days }\end{array}$ & $\begin{array}{l}\uparrow \text { islet cells number, } \\
\uparrow \text { insulin positive cells }\end{array}$ & $\begin{array}{l}\downarrow \mathrm{FBG}, \uparrow \text { serum } \\
\text { insulin, } \uparrow \mathrm{C} \text {-peptide }\end{array}$ & $\begin{array}{l}\text { Abdel Aziz et al., } \\
2013\end{array}$ \\
\hline \multirow[b]{2}{*}{ Crocus sativus } & \multirow[b]{2}{*}{$\begin{array}{l}\text { ALO-induced } \\
\text { diabetic rats }\end{array}$} & $\begin{array}{l}\text { Ethanolic extract of } \\
\text { stigmas }(40 \mathrm{mg} / \mathrm{kg} \text {, } \\
\text { IP) for } 14 \text { days }\end{array}$ & $\begin{array}{l}\uparrow \text { beta cell number, } \\
\uparrow \text { immunoreactivity of } \\
\text { insulin in beta cells }\end{array}$ & $\begin{array}{l}\downarrow \text { FBG, } \uparrow \text { serum } \\
\text { insulin }\end{array}$ & $\begin{array}{l}\text { Mohajeri, Mousavi, } \\
\text { Doustar, } 2009\end{array}$ \\
\hline & & $\begin{array}{l}\text { Ethanolic extract } \\
\text { (200 - } 600 \mathrm{mg} / \mathrm{kg} \text {, } \\
\text { PO) for } 4 \text { weeks }\end{array}$ & $\begin{array}{l}\text { The animals had } \\
\text { normal histological } \\
\text { structure } \\
\text { (at } 600 \mathrm{mg} / \mathrm{kg} \text { ) }\end{array}$ & $\begin{array}{l}\downarrow \text { FBG, } \downarrow \text { serum } \\
\text { lipids, } \downarrow \text { weight lost, } \\
\uparrow \text { serum insulin, } \\
\text { improved kidney and } \\
\text { liver function }\end{array}$ & Elgazar et al., 2013 \\
\hline
\end{tabular}


TABLE I - Phytochemicals with protective/regenerative effects on pancreatic beta cells. (cont.)

\begin{tabular}{|c|c|c|c|c|c|}
\hline Plants & Animal model & Treatment & Effects on pancreas & Other effects & Reference \\
\hline $\begin{array}{l}\text { Elephantopus } \\
\text { scaber }\end{array}$ & $\begin{array}{l}\text { ALO-induced } \\
\text { diabetic rats }\end{array}$ & $\begin{array}{l}\text { Aqueous extract of } \\
\text { root and leaves } \\
(0.3 \mathrm{~g} / \mathrm{kg}, \mathrm{PO}) \text { for } \\
12 \text { weeks }\end{array}$ & $\begin{array}{l}\uparrow \text { beta cell number per } \\
\text { islet }\end{array}$ & $\begin{array}{l}\downarrow \text { FBG }, \downarrow \text { serum } \\
\text { lipids, } \downarrow \text { serum urea, } \\
\downarrow \text { creatinine }\end{array}$ & $\begin{array}{l}\text { Daisy, Rayan, } \\
\text { Rajathi, } 2007\end{array}$ \\
\hline Epicatechin & $\begin{array}{l}\text { ALO-induced } \\
\text { diabetic rats }\end{array}$ & $\begin{array}{l}\text { Epicatechin } \\
(30 \mathrm{mg} / \mathrm{kg} \text {, twice } \\
\text { daily, IP) for } 4-5 \text { days }\end{array}$ & $\begin{array}{l}\uparrow \text { beta cell number per } \\
\text { islet }\end{array}$ & $\begin{array}{l}\downarrow \text { FBG, } \uparrow \text { serum } \\
\text { insulin }\end{array}$ & $\begin{array}{c}\text { Chakravarthy, } \\
\text { Gupta, Gode, } 1982\end{array}$ \\
\hline \multirow{3}{*}{$\begin{array}{l}\text { Gymnema } \\
\text { sylvestre }\end{array}$} & & $\begin{array}{l}\text { Water soluble extract } \\
\text { of leaves }\end{array}$ & $\begin{array}{l}\uparrow \text { islets number, } \uparrow \text { beta } \\
\text { cell number }\end{array}$ & $\begin{array}{l}\downarrow \mathrm{FBG}, \uparrow \text { serum } \\
\text { insulin }\end{array}$ & $\begin{array}{c}\text { Shanmugasundaram } \\
\text { et al., } 1990\end{array}$ \\
\hline & $\begin{array}{l}\text { STZ-induced } \\
\text { diabetic rats }\end{array}$ & $\begin{array}{l}\text { Standardized extract } \\
\text { of leaves }(200 \& \\
400 \mathrm{mg} / \mathrm{kg}, \mathrm{PO}) \\
\text { for } 40 \text { days }\end{array}$ & $\begin{array}{l}\downarrow \text { congestion, } \uparrow \text { normal } \\
\text { beta cells }\end{array}$ & $\begin{array}{l}\downarrow \mathrm{FBG}, \downarrow \text { HbA1c, } \\
\downarrow \text { serum lipids, } \\
\downarrow \text { weight lost, } \uparrow \text { serum } \\
\text { insulin, } \uparrow \text { glycogen } \\
\text { content in liver }\end{array}$ & $\begin{array}{l}\text { Aralelimath, } \\
\text { Bhise, } 2012\end{array}$ \\
\hline & $\begin{array}{l}\text { ALO-induced } \\
\text { diabetic rats }\end{array}$ & $\begin{array}{l}\text { Methanol extract of } \\
\text { leaves and callus } \\
\text { for } 45 \text { days }\end{array}$ & $\begin{array}{l}\uparrow \text { beta cell } \\
\text { regeneration }\end{array}$ & $\begin{array}{l}\uparrow \text { body weight, } \\
\uparrow \text { glycogen content } \\
\text { in liver }\end{array}$ & $\begin{array}{c}\text { Ahmed, Rao, Rao, } \\
2010\end{array}$ \\
\hline \multirow{4}{*}{ Juglans regia } & \multirow{2}{*}{$\begin{array}{l}\text { ALO-induced } \\
\text { diabetic rats }\end{array}$} & $\begin{array}{l}\text { Diet supplemented } \\
\text { with } 60 \mathrm{~g} / \mathrm{kg} \text { of } \\
\text { leaves for } 15 \text { days }\end{array}$ & $\begin{array}{l}\uparrow \text { islets density, } \\
\uparrow \text { percent of beta cells, } \\
\uparrow \text { islets size }\end{array}$ & $\downarrow \mathrm{FBG}$ & $\begin{array}{l}\text { Jelodar, Mohsen, } \\
\text { Shahram, } 2007\end{array}$ \\
\hline & & $\begin{array}{l}\text { Ethanolic extract of } \\
\text { leaf }(200 \mathrm{mg} / \mathrm{kg})\end{array}$ & $\begin{array}{l}\text { Enlargement of islets } \\
\text { size }\end{array}$ & $\begin{array}{l}\uparrow \text { serum insulin, } \\
\downarrow \text { HbA1c }\end{array}$ & Asgary et al., 2008 \\
\hline & \multirow{2}{*}{$\begin{array}{l}\text { STZ-induced } \\
\text { diabetic rats }\end{array}$} & $\begin{array}{l}\text { Methanolic extract } \\
\text { of leaves or peel } \\
(200 \mathrm{mg} / \mathrm{kg}, \mathrm{PO}) \\
\text { for } 4 \text { weeks }\end{array}$ & $\uparrow$ beta cell number & $\begin{array}{l}\downarrow \mathrm{FBG}, \uparrow \text { serum } \\
\text { insulin, } \downarrow \text { HbA1c }\end{array}$ & $\begin{array}{l}\text { Javidanpour et al., } \\
2012\end{array}$ \\
\hline & & $\begin{array}{l}\text { Aqueous extract of } \\
\text { shell septum ( } 200 \text { - } \\
800 \mathrm{mg} / \mathrm{kg}, \text { PO) } \mathrm{f} \\
\text { or } 4 \text { weeks }\end{array}$ & No effect & $\downarrow$ FBG & $\begin{array}{c}\text { Dehghani, } \\
\text { Mashhoody, } \\
\text { Panjehshahin, } 2012\end{array}$ \\
\hline $\begin{array}{l}\text { Leucaena } \\
\text { leucocephala }\end{array}$ & $\begin{array}{l}\text { STZ-induced } \\
\text { diabetic rats }\end{array}$ & $\begin{array}{l}\text { Extract of seed } \\
(0.25-1 \mathrm{~g} / \mathrm{kg}, \mathrm{PO}) \\
\text { for } 14 \text { days }\end{array}$ & $\begin{array}{l}\uparrow \text { beta cell number per } \\
\text { islets, } \uparrow \text { islets diameter }\end{array}$ & $\begin{array}{l}\downarrow \mathrm{FBG}, \downarrow \text { serum } \\
\text { lipids }\end{array}$ & $\begin{array}{c}\text { Darmono } \\
\text { Syamsudin, } \\
\text { Simanjuntak, } 2006\end{array}$ \\
\hline Mangiferin & $\begin{array}{l}\text { Partial } \\
\text { pancreatectomy- } \\
\text { induced diabetic } \\
\text { mice }\end{array}$ & $\begin{array}{l}\text { Mangiferin }(30 \& \\
90 \mathrm{mg} / \mathrm{kg}, \mathrm{IP}) \\
\text { for } 14 \text { days }\end{array}$ & $\begin{array}{l}\uparrow \text { beta cell } \\
\text { hyperplasia, } \uparrow \text { beta } \\
\text { cell proliferation, } \\
\downarrow \text { beta cell apoptosis }\end{array}$ & $\begin{array}{l}\downarrow \mathrm{FBG}, \uparrow \text { serum } \\
\text { insulin, } \uparrow \text { glucose } \\
\text { tolerance }\end{array}$ & Wang et al., 2014 \\
\hline \multirow{4}{*}{$\begin{array}{l}\text { Momordica } \\
\text { charantia }\end{array}$} & $\begin{array}{l}\text { STZ-induced } \\
\text { diabetic rats }\end{array}$ & $\begin{array}{l}\text { Fruit juice } \\
(10 \mathrm{~mL} / \mathrm{kg}, \mathrm{PO}) \\
\text { for } 10 \mathrm{weeks} \\
\end{array}$ & $\uparrow$ beta cell number & $\uparrow$ serum insulin & Ahmed et al., 1998 \\
\hline & \multirow{2}{*}{$\begin{array}{l}\text { ALO-induced } \\
\text { diabetic rats }\end{array}$} & $\begin{array}{l}\text { Acetone extract of } \\
\text { fruit }(250-750 \mathrm{mg} / \mathrm{kg} \text {, } \\
\text { PO) for } 30 \text { days }\end{array}$ & $\begin{array}{l}\text { Recovery of beta } \\
\text { cells of the islets of } \\
\text { Langerhans }\end{array}$ & Hepatoprotection & $\begin{array}{l}\text { Singh, Gupta, } \\
\text { 2007b }\end{array}$ \\
\hline & & $\begin{array}{l}\text { Alcoholic extract of } \\
\text { fruit }(250-750 \mathrm{mg} / \mathrm{kg} \text {, } \\
\text { PO) for } 30 \text { days }\end{array}$ & $\begin{array}{l}\text { Recovery of beta } \\
\text { cells of the islets of } \\
\text { Langerhans }\end{array}$ & $\downarrow \mathrm{FBG}$ & Singh et al., 2008 \\
\hline & $\begin{array}{l}\text { Neonatal STZ- } \\
\text { induced type-2 } \\
\text { diabetic rats } \\
\end{array}$ & $\begin{array}{l}\text { Aqueous extract of } \\
\text { fruit }(20 \mathrm{mg} / \mathrm{kg}, \mathrm{PO}) \\
\text { for } 4 \text { weeks }\end{array}$ & $\begin{array}{l}\text { ¡beta cell number per } \\
\text { islet }\end{array}$ & $\begin{array}{l}\downarrow \mathrm{FBG}, \uparrow \text { serum } \\
\text { insulin }\end{array}$ & $\begin{array}{l}\text { Abdollahi et al., } \\
2011\end{array}$ \\
\hline
\end{tabular}


TABLE I - Phytochemicals with protective/regenerative effects on pancreatic beta cells. (cont.)

\begin{tabular}{|c|c|c|c|c|c|}
\hline Plants & Animal model & Treatment & Effects on pancreas & Other effects & Reference \\
\hline $\begin{array}{l}\text { Momordica } \\
\text { charantia }\end{array}$ & $\begin{array}{l}\text { Neonatal STZ- } \\
\text { induced type- } 2 \\
\text { diabetic rats }\end{array}$ & $\begin{array}{l}\text { Ethanolic extract of } \\
\text { fruit }(400 \mathrm{mg} / \mathrm{kg}, \mathrm{PO}) \\
\text { for } 4 \text { weeks }\end{array}$ & $\begin{array}{l}\uparrow \text { islet size, } \uparrow \text { total beta } \\
\text { cell area, } \uparrow \text { beta cell } \\
\text { number }\end{array}$ & $\begin{array}{l}\downarrow \mathrm{FBG}, \uparrow \text { serum } \\
\text { insulin }\end{array}$ & $\begin{array}{l}\text { Hafizur, Kabir, } \\
\text { Chishti, } 2011\end{array}$ \\
\hline Morus alba & $\begin{array}{l}\text { STZ-induced } \\
\text { diabetic rats }\end{array}$ & $\begin{array}{l}\text { Ethanolic extract of } \\
\text { leaves }(400 \& \\
600 \mathrm{mg} / \mathrm{kg}, \mathrm{PO}) \\
\text { for } 35 \text { days }\end{array}$ & $\begin{array}{l}\text { } \text { islets diameter, } \\
\uparrow \text { beta cell number }\end{array}$ & $\downarrow \mathrm{FBG}$ & $\begin{array}{l}\text { Mohammadi, } \\
\text { Prakash, } 2008\end{array}$ \\
\hline \multirow{6}{*}{$\begin{array}{l}\text { Nigella sativa \& } \\
\text { Thymoquinone }\end{array}$} & \multirow{5}{*}{$\begin{array}{l}\text { STZ-induced } \\
\text { diabetic rats }\end{array}$} & $\begin{array}{l}\text { Volatile oil } \\
(0.2 \mathrm{~mL} / \mathrm{kg}, \mathrm{IP}) \\
\text { for } 30 \text { days }\end{array}$ & $\begin{array}{l}\text { Regeneration/ } \\
\text { proliferation of } \\
\text { pancreatic } \beta \text {-cells }\end{array}$ & $\begin{array}{l}\downarrow \mathrm{FBG}, \uparrow \text { serum } \\
\text { insulin }\end{array}$ & Kanter et al., 2003 \\
\hline & & $\begin{array}{l}\text { Volatile oil } \\
(0.2 \mathrm{~mL} / \mathrm{kg}, \mathrm{IP}) \\
\text { for } 30 \text { days } \\
\end{array}$ & $\begin{array}{l}\text { Preserving beta cell } \\
\text { numbers, } \downarrow \text { oxidative } \\
\text { stress }\end{array}$ & $\begin{array}{l}\downarrow \text { oxidative stress } \\
\text { parameters in blood }\end{array}$ & Kanter et al., 2004 \\
\hline & & $\begin{array}{l}\text { Thymoquinone } \\
(50 \mathrm{mg} / \mathrm{kg}, \mathrm{PO}) \\
\text { for } 4 \text { weeks }\end{array}$ & $\begin{array}{l}\downarrow \text { islet degeneration } \\
\text { and necrosis }\end{array}$ & $\begin{array}{l}\downarrow \text { FBG, } \uparrow \text { serum } \\
\text { insulin }\end{array}$ & Kanter, 2009 \\
\hline & & $\begin{array}{l}\text { N. sativa oil } \\
(0.2 \mathrm{~mL} / \mathrm{kg}) \\
\text { for } 30 \text { days }\end{array}$ & $\uparrow$ islets diameter & $\begin{array}{l}\downarrow \text { FBG, } \uparrow \text { serum } \\
\text { insulin }\end{array}$ & Albajali et al., 2011 \\
\hline & & $\begin{array}{l}\text { Aqueous extract } \\
(2 \mathrm{~mL} / \mathrm{kg}, \mathrm{IP}) \text {, oil } \\
(0.2 \mathrm{~mL} / \mathrm{kg}, \mathrm{IP}) \text { or } \\
\text { thymoquinone } \\
(3 \mathrm{mg} / \mathrm{kg}, \mathrm{IP}) \text { for } \\
30 \text { days }\end{array}$ & $\begin{array}{l}\downarrow \text { oxidative stress } \\
\text { indexes, partial } \\
\text { regeneration of the } \\
\text { islets and beta cells }\end{array}$ & $\begin{array}{l}\downarrow \mathrm{FBG}, \uparrow \text { serum } \\
\text { insulin }\end{array}$ & $\begin{array}{l}\text { Abdelmeguid } \text { et al., } \\
2010\end{array}$ \\
\hline & $\begin{array}{l}\text { STZ + } \\
\text { nicotinamide- } \\
\text { induced diabetic } \\
\text { rats }\end{array}$ & $\begin{array}{l}\text { Thymoquinone } \\
(80 \mathrm{mg} / \mathrm{kg}) \\
\text { for } 45 \text { days }\end{array}$ & $\begin{array}{l}\text { Preservation of islet } \\
\text { cells against beta cell } \\
\text { damage }\end{array}$ & $\begin{array}{l}\downarrow \text { } \text { oxidative stress in } \\
\text { liver and kidney }\end{array}$ & $\begin{array}{c}\text { Sankaranarayanan, } \\
\text { Pari, } 2011\end{array}$ \\
\hline $\begin{array}{l}\text { Prangos } \\
\text { ferulacea }\end{array}$ & $\begin{array}{l}\text { STZ-induced } \\
\text { diabetic rats }\end{array}$ & $\begin{array}{l}\text { Hydroalcoholic } \\
\text { extract of leaves, } \\
\text { stem and root } \\
(100 \mathrm{mg} / \mathrm{kg}, \mathrm{PO}) \\
\text { for one month }\end{array}$ & $\begin{array}{l}\downarrow \text { lymphocytes } \\
\text { infiltration, } \downarrow \text { necrotic } \\
\text { cells, regeneration of } \\
\text { islets }\end{array}$ & $\begin{array}{l}\downarrow \text { FBG }, \downarrow \text { weight loss, } \\
\downarrow \mathrm{HbA} 1 \mathrm{c}\end{array}$ & $\begin{array}{c}\text { Soltani Band et al., } \\
2011\end{array}$ \\
\hline $\begin{array}{l}\text { Pterocarpus } \\
\text { marsupium }\end{array}$ & $\begin{array}{l}\text { ALO-induced } \\
\text { diabetic rats }\end{array}$ & $\begin{array}{l}\text { A flavonoid fraction } \\
\text { extracted from the } \\
\text { bark }\end{array}$ & $\begin{array}{l}\text { Regeneration of beta } \\
\text { cells }\end{array}$ & $\downarrow F B G$ & $\begin{array}{c}\text { Chakravarthy et al., } \\
1980\end{array}$ \\
\hline $\begin{array}{l}\text { Sansevieria } \\
\text { trifasciata }\end{array}$ & $\begin{array}{l}\text { ALO-induced } \\
\text { diabetic rats }\end{array}$ & $\begin{array}{l}\text { Decoction of leaves } \\
(100-200 \mathrm{mg} / \mathrm{kg} \\
\text { PO) for } 30 \text { days }\end{array}$ & $\begin{array}{l}\uparrow \text { granule density in } \\
\text { beta cells of islets }\end{array}$ & $\downarrow \mathrm{FBG}$ & $\begin{array}{l}\text { Qomariyah, Sarto, } \\
\text { Pratiwi, } 2012\end{array}$ \\
\hline Solanum nigrum & $\begin{array}{l}\text { ALO-induced } \\
\text { diabetic rats }\end{array}$ & $\begin{array}{l}\text { Aqueous extract of } \\
\text { leaves }(400 \mathrm{mg} / \mathrm{kg}) \\
\text { for } 21 \text { days }\end{array}$ & $\begin{array}{l}\text { Partial restoration of } \\
\text { islets population and } \\
\text { hyperplasia of islet } \\
\text { cells }\end{array}$ & $\downarrow \mathrm{FBG}$ & $\begin{array}{c}\text { Maniyar, } \\
\text { Umamageswari, } \\
\text { Karthikeyan, } 2012\end{array}$ \\
\hline Syzygium cumini & $\begin{array}{l}\text { ALO-induced } \\
\text { diabetic rats }\end{array}$ & $\begin{array}{l}\text { Alcoholic extract of } \\
\text { seeds }(250-750 \mathrm{mg} / \mathrm{kg} \text {, } \\
\text { PO) for } 30 \text { days }\end{array}$ & $\begin{array}{l}\text { Hypertrophy of } \\
\text { certain islets, } \\
\uparrow \text { granule density in } \\
\text { beta cells }\end{array}$ & $\begin{array}{l}\downarrow F B G, \uparrow \text { body } \\
\text { weight, }\end{array}$ & Singh, Gupta, 2007a \\
\hline
\end{tabular}


TABLE I - Phytochemicals with protective/regenerative effects on pancreatic beta cells. (cont.)

\begin{tabular}{|c|c|c|c|c|c|}
\hline Plants & Animal model & Treatment & Effects on pancreas & Other effects & Reference \\
\hline $\begin{array}{l}\text { Teucrium } \\
\text { polium }\end{array}$ & $\begin{array}{l}\text { STZ-induced } \\
\text { diabetic rats }\end{array}$ & $\begin{array}{l}\text { Hydroalcoholic } \\
\text { extract (equivalent to } \\
0.5 \mathrm{~g} \text { plant } / \mathrm{kg}, \mathrm{PO}) \\
\text { for } 6 \text { weeks }\end{array}$ & $\begin{array}{l}\uparrow \text { islets number, } \\
\uparrow \text { beta cell number, } \\
\downarrow \text { lymphocytes and } \\
\text { macrophages number }\end{array}$ & $\begin{array}{l}\downarrow \text { FBG, } \downarrow \text { bilirubin, } \\
\downarrow \text { glutamate } \\
\text { oxaloacetate } \\
\text { transferase, } \\
\downarrow \text { glutamate pyruvate } \\
\text { transferase, } \uparrow \text { serum } \\
\text { insulin }\end{array}$ & $\begin{array}{c}\text { Yazdanparast, } \\
\text { Esmaeili, Ashrafi, } \\
2005\end{array}$ \\
\hline $\begin{array}{l}\text { Tinospora } \\
\text { cordifolia }\end{array}$ & $\begin{array}{l}\text { STZ-induced } \\
\text { diabetic rats }\end{array}$ & $\begin{array}{l}\text { Methanolic extract } \\
\text { of stem }(250 \mathrm{mg} / \mathrm{kg} \text {, } \\
\text { PO) for } 100 \text { days }\end{array}$ & $\begin{array}{l}\text { Regeneration of beta } \\
\text { cells }\end{array}$ & $\begin{array}{l}\downarrow \mathrm{FBG}, \downarrow \mathrm{HbA} 1 \mathrm{c}, \\
\uparrow \text { serum insulin, } \\
\uparrow \mathrm{C} \text {-peptide }\end{array}$ & $\begin{array}{l}\text { Rajalakshmi et al., } \\
2009\end{array}$ \\
\hline $\begin{array}{l}\text { Trigonella } \\
\text { foenum- } \\
\text { graceum }\end{array}$ & $\begin{array}{l}\text { Neonatal STZ- } \\
\text { induced type- } 2 \\
\text { diabetic rats }\end{array}$ & $\begin{array}{l}\text { Hydroalcoholic } \\
\text { extract of seeds } \\
(100 \mathrm{mg} / \mathrm{kg}, \mathrm{PO}) \\
\text { for } 28 \text { days }\end{array}$ & $\begin{array}{l}\text { 个beta cell number, } \\
\uparrow \text { islet size }\end{array}$ & $\begin{array}{l}\downarrow \text { FBG }, \downarrow \text { weight lost, } \\
\downarrow \text { HbA } 1 \mathrm{c}, \uparrow \text { serum } \\
\text { insulin }\end{array}$ & Kulkarni et al., 2012 \\
\hline \multirow{2}{*}{$\begin{array}{l}\text { Vernonia } \\
\text { amygdalina }\end{array}$} & \multirow{2}{*}{$\begin{array}{l}\text { ALO-induced } \\
\text { diabetic rats }\end{array}$} & $\begin{array}{l}\text { Pre-treated with } \\
\text { aqueous extract } \\
(250 \mathrm{mg} / \mathrm{kg}, \mathrm{PO}) \\
\text { for } 21 \text { days }\end{array}$ & $\begin{array}{l}\text { Moderate } \\
\text { regeneration of islets }\end{array}$ & $\downarrow$ FBG & Sunday et al., 2012 \\
\hline & & $\begin{array}{l}\text { Ethanolic extract of } \\
\text { leaves }(400 \mathrm{mg} / \mathrm{kg} \text {, } \\
\text { PO) for } 14 \text { days }\end{array}$ & $\begin{array}{l}\text { Regeneration of new } \\
\text { islet cells }\end{array}$ & $\begin{array}{l}\downarrow \text { FBG }, \downarrow \text { serum } \\
\text { alpha-amylase } \\
\text { activity }\end{array}$ & $\begin{array}{l}\text { Atangwho et al., } \\
2007\end{array}$ \\
\hline Vinca rosea & & $\begin{array}{l}\text { Methanolic extract } \\
\text { of leaves }(300 \& \\
500 \mathrm{mg} / \mathrm{kg}, \mathrm{PO}) \\
\text { for } 14 \text { days }\end{array}$ & $\begin{array}{l}\text { Partial restoration } \\
\text { of normal cellular } \\
\text { population and } \\
\text { enlarged size of beta } \\
\text { cells }\end{array}$ & $\begin{array}{l}\downarrow \mathrm{FBG}, \uparrow \text { glucose } \\
\text { tolerance, } \downarrow \text { serum } \\
\text { lipids, } \downarrow \text { weight lost, } \\
\downarrow \text { creatinine, } \downarrow \text { urea, } \\
\downarrow \text { alkalin phosphatase }\end{array}$ & Ahmed et al., 2010 \\
\hline Urtica pilulifera & $\begin{array}{l}\text { STZ-induced } \\
\text { diabetic rats }\end{array}$ & $\begin{array}{l}\text { Lectin isolated from } \\
\text { seeds }(100 \mathrm{mg} / \mathrm{kg}, \mathrm{IP}) \\
\text { for } 4 \text { weeks }\end{array}$ & $\begin{array}{l}\downarrow \text { cellular damage in } \\
\text { pancreas }\end{array}$ & $\downarrow$ FBG,$\downarrow$ weight lost & Kavalali et al., 2003 \\
\hline
\end{tabular}

ALO: alloxan; FBG: fasting blood glucose; HDL: high density lipoprotein; IP: intraperitoneal injection; PO (Per os): oral administration; STZ: streptozotocin; TG: triglyceride; $\downarrow$ : decrease; $\uparrow:$ increase

fasting blood glucose (FBG) and lipids in diabetic patients (Ghorbani, 2013a, b). According to the animal studies, it may also induce a protective/regenerative effect on pancreatic beta cells. Albajali et al. (2011) reported that the aqueous extract of $A$. sativum increased the diameter of pancreatic islets in STZ-induced diabetic rats. In another study, intraperitoneal injection of $A$. sativum oil decreased beta cell degeneration and level of anti-islet antibodies in the animals with T1D (Osman et al., 2012). Alashkham et al. (2013) also showed regenerative action of this oil in the pancreatic islets of diabetic rats. Yet, in another study, there was no significant difference between the histopathology of the pancreas of garlic treated and untreated diabetic rats (Jelodar et al., 2005).

Allicin is the major active component of $A$. sativum and a precursor of many secondary compounds formed in crushed garlic preparations or aged garlic. This compound has been proposed to be responsible for the health promotion benefits of A. sativum and protective actions in pancreatic islets (Osman et al., 2012). 


\section{Anastatica hierochuntica}

Anastatica hierochuntica from Brassicaceae family is commonly called "Kaff Maryam" or "Rose of Jericho" and is one of the folk medicinal plants, which is widely used in Arab countries (Daur, 2012; Shaban, AlAzzawie, Mohamme, 2011). Experimental studies have demonestrated that aqueous and methanolic extracts of $A$. hierochuntica have antioxidative, hypoglycemic, and hypolipidemic effects in diabetic rats (Rahmy, El-Ridi, 2002; Shaban, Al-Azzawie, Mohamme, 2011). This hypoglycemic action may be due to its beneficial effects on pancreatic beta cells. Rahmy, El-Ridi (2002) reported that $A$. hierochuntica increased the number of beta cells in pancreatic islets of diabetic rats. Similarly, Shaban, Al-Azzawie, Mohamme (2011) showed that this plant enhanced volume density of islets and percentage of beta cells in diabetic rats.

\section{Annona muricata}

Annona muricata from Annonaceae family (commonly called Soursop) is a small tree, all parts of which are used in natural medicine in the tropical areas in South and North America and west of Africa (Adewole, Caxton-Martins, 2006). According to the animal studies on STZ-induced diabetic rats, the administration of extract of $A$. muricata leaves can increase the number of islets and beta cells in pancreas (Adewole, Caxton-Martins, 2006; Adeyemi et al., 2008).

\section{Azadirachta indica}

Neem (Azadirachta indica), a tree in the mahogany family, is among the well-known medicinal plants in Africa. Using a clinical study, its hypoglycemic and hypolipidemic effects among diabetic patients have been shown in recent years (Kochhar, Sharma, Schdeva, 2009; Kumari, 2010). Two animal studies have demonstrated that $A$. indica has also a regenerative effect on the islets of Langerhans. According to the report by Akinola, CaxtonMartins, Dini (2010), oral feeding of ethanolic extract of A. indica leaves increased beta cell density and decreased oxidative stress in the pancreas of STZ-induced diabetic rats. Ebong et al. (2006) also showed regenerative action of this extract in alloxan-induced diabetic rats.

\section{Berberine}

Berberine is an isoquinoline alkaloid which is present in the root, rhizome, and stem bark of many plants, such as Berberis vulgaris, Coptidis rhizoma, Hydrastis canadensis, Mahonia aquifolium, and Mohonia nervosa (Ye et al., 2009). Berberine has been demonstrated to have beneficial effects on hyperglycemia and dyslipidemia in diabetic patients (Yin et al., 2008). Regarding its protective/regenerative effect on pancreas, Tang et al. (2006) demonstrated that oral administration of berberine decreased the levels of FBG and serum lipids and restored the damage of pancreas tissue in alloxan-induced diabetic rats. Another study reported that berberine increased insulin sensitization, insulin secretion, and beta cell regeneration in STZ- and high carbohydrate/fat dietinduced diabetic rats (Zhou et al., 2009).

\section{Crocus sativus}

Saffron (Crocus sativus) is a perennial stemless herb of the Iridaceae family which is widely cultivated in Iran and also in some other countries such as India. Crocin (crocetin glycoside) and safranal $\left(\mathrm{C}_{10} \mathrm{H}_{14} \mathrm{O}\right)$ are the main constituents of $C$. sativus and responsible for the pharmacological effects of this plant. Safranal has been reported to have a number of medicinal attributes including antioxidative and cytoprotective effects (Alinejad, Ghorbani, Sadeghnia, 2013; Sadeghnia et al., 2013). Safranal, C. sativus, and crocin show antihyperglycemic, hypolipidemic, and blood insulin elevating effects in insulin-dependent diabetic animals (Kianbakht, Hajiaghaee, 2011; Mohajeri, Mousavi, Doustar, 2009; Samarghandian et al., 2013). In addition, C. sativus has beneficial effects on the histological structure of pancreas in alloxan-induced diabetic rats (Elgazar, Rezq, Bukhari, 2013). Recovery of beta cells and increase of insulin immunoreactivity are of beneficial effects induced by C. sativus in the islets of Langerhans of diabetic rats (Mohajeri, Mousavi, Doustar, 2009).

\section{Curcumin}

Curcumin (diferuloylmethane) is an active ingredient of Curcuma longa, a spice employed as a flavoring and coloring supplement in foods. Evidence has suggested that it has potent antioxidant and cytoprotective effects (Alinejad, Ghorbani, Sadeghnia, 2013; Park et al., 2008). In diabetic rats, curcumin inhibits lymphocytes infiltration in the islets of Langerhans and keeps the number of islets and beta cells (Chanpoo, Petchpiboonthai, 2010; Abdel Aziz et al., 2013). These effects are accompanied by decreased FBG and increased serum insulin and C-peptide (Abdel Aziz et al., 2013).

\section{Gymnema sylvestre}

Accumulating evidence has demonstrated that $G$. sylvestre (commonly known as Gurmar in India) improves glycemic control in both T1D and T2D. Clinical trials have demonstrated that the administration of this herb decreases FBG, PPBG, and HbAlc in diabetic patients (Ghorbani, 
2013b). The potential ability of $G$. sylvestre in regenerating pancreatic beta cells has been tested in recent years. It has been shown that aqueous extract of $G$. sylvestre leaves increases serum insulin level in streptozotocin treated rats. This effect is accompanied by a double increase in the number of beta cells (Shanmugasundaram et al., 1990). Regenerative effect of G. sylvestre has been also observed following long-term treatment of diabetic rats using a standardized dry extract of leaves (Aralelimath, Bhise, 2012). Gymnemic acid is considered to be the active ingredient responsible for the regenerative action of $G$. sylvestre on beta cells (Ahmed, Rao, Rao, 2010).

\section{Juglans regia}

Juglans regia (walnut) has been widely used in the traditional medicine of Asian countries as a remedy for various ailments. Its leaves have shown a significant hypoglycemic effect in diabetic animals. Increase of hepatic glycogenolysis, decrease of gluconeogenesis, inhibition of glucose absorption from the intestine, and enhancing serum insulin are the proposed mechanisms for hypoglycemic effect of $J$. regia (Asgary et al., 2008; Kamyab et al., 2010; Jelodar, Mohsen, Shahram, 2007). Increase of insulin level can be mediated through regenerative actions of $J$. regia on pancreatic islets. It has been shown that density of islets, percent of beta cells, and islets size significantly increase in pancreatic tissue of diabetic rats receiving walnut leaf (Jelodar, Mohsen, Shahram, 2007). Regenerative property of J. regia is accompanied by increase in the serum insulin level (Asgary et al., 2008; Javidanpour et al., 2012). Yet, in contrast to leaf, treatment with the shell septum of $J$. regia has no effects on the pancreatic structure of diabetic rats (Dehghani, Mashhoody, Panjehshahin, 2012).

\section{Momordica charantia}

Momordica charantia (Karela, Ampalaya, bitter melon) has acquired a reputation for the management of diabetes. It has passed several animal and clinical studies and its beneficial effects on blood glucose and lipids have been shown in diabetic patients since 36 years ago (Ghorbani, 2013b). Effect of M. charantia fruit on pancreatic histopathological changes has been determined by at least five experimental studies. In adult diabetic animals, the results indicate that $M$. charantia increases the number of beta cells per islets and leads to the neoformation of islets from the pre-existing islet cells (Ahmed et al., 1998; Singh, Gupta, 2007b; Singh et al., 2008). In addition, the hypoglycemic effect of $M$. charantia remains after the cease of treatment (Singh et al., 2008). In neonatal diabetic rats, administration of aqueous or ethanolic extract of $M$. charantia fruit alleviates pancreatic damage and induces the renewal of pancreatic beta cells (Abdollahi et al., 2011; Hafizur, Kabir, Chishti, 2011).

\section{Nigella sativa}

$N$. sativa (black seed) has been used for centuries as a natural remedy for various ailments. Hypoglycemic and hypolipidemic effects of black seed have been reported in diabetic patients (Ghorbani, 2013a). Kanter et al. (2003) investigated the effect of $N$. sativa volatile oil on histopathology of pancreatic beta cells in diabetic rats and found that $N$. sativa treatment decreased the elevated serum glucose, increased the insulin concentration, and partially regenerated pancreatic beta cells in these animals. Afterward, they showed that the beneficial effect of $N$. sativa on the number of beta cells was accompanied by decreasing lipid peroxidation and increasing antioxidant enzyme activity (Kanter et al., 2004). In another experiment, it was represented that the administration of $N$. sativa oil to STZ-induced diabetic rats increased the diameter of islets of Langerhans (Albajali et al., 2011). The protective effect of $N$. sativa against beta cell destruction is attributed to its active constituent, thymoquinone. Treatment with thymoquinone inhibits STZ-induced islet degeneration and necrosis and leads to the partial regeneration of the islet and beta cells of diabetic animals (Abdelmeguid et al., 2010; Kanter, 2009; Sankaranarayanan, Pari, 2011).

\section{Vernonia amygdalina}

Vernonia amygdalina, also called bitter leaf, is a vegetable from compositae family and is commonly used in west of Africa for treating various diseases including diabetes (Atangwho et al., 2007). Pre-treatment with the aqueous extract of $V$. amygdalina protects the islets of Langerhans against alloxan-induced pancreatic degeneration (Sunday et al., 2012). Also, administration of $V$. amygdalina induces regeneration of the islet cells and decreases FBG in diabetic rats (Atangwho et al., 2007).

\section{Other plants with protective effects on pancreas}

In addition to the above-mentioned herbs, a number of others has been found to have potential protective or regenerative properties on beta cells: Abroma augusta (Mir, Darzi, Mir, 2013), Alchornea cordifolia (EliakimIkechukwu, Obri, 2009), Amaranthus caudatus (Girija et al., 2011), Amaranthus spinosus (Girija et al., 2011), Amaranthus viridis (Girija et al., 2011), Artanema sesamoides (Selvan et al., 2008), Bauhinia variegata (Koti 
et al., 2009), Cassia alata (Eliakim-Ikechukwu et al., 2013), Cassia occidentalis (Verma et al., 2010), Clitoria ternatea (Verma, Itankar, Arora , 2013), Elephantopus scaber (Daisy et al., 2007), Epicatechin (Chakravarthy, Gupta, Gode, 1982), Leucaena leucocephala (DarmonoSyamsudin, Simanjuntak, 2006), Mangiferin (Wang et al., 2014), Morus alba (Mohammadi, Prakash, 2008), Prangos ferulacea (Soltani Band et al., 2011), Pterocarpus marsupium (Chakravarthy et al., 1980), Sansevieria trifasciata (Qomariyah, Sarto, Pratiwi, 2012), Syzygium cumini (Singh, Gupta, 2007a), Teucrium polium (Yazdanparast, Esmaeili, Ashrafi, 2005), Thunbergia laurifolia (Aritajat, Wuteerapol, Saenphet,, 2004), Tinospora cordifolia (Rajalakshmi et al., 2009), Trigonella foenum-graceum (Kulkarni et al., 2012), Vinca rosea (Ahmed et al., 2010), Urtica dioica (Golalipour et al., 2010), and Urtica pilulifera (Kavalali et al., 2003). However, for each one, only one study from independent authors was found to support their protective or regenerative effects on beta cells. Therefore, further studies are needed to establish the therapeutic value of these herbs in the management of insulin-dependent diabetes.

\section{Proposed mechanisms for protective/regenerative effect of phytochemicals}

In this review, the protective effects of several plants on drug-induced $\beta$-cells destruction, increasing islets size, and beta cell population were presented. Although these pieces of evidence did not fully reveal the involved molecular mechanisms, decreasing apoptosis, increasing cells' antioxidant capacity, and immunomodulation wee the postulated mechanisms of action.

Beta cell apoptosis and replication rates, islet size, and islet neogenesis are the major determinants of pancreatic endocrine capability for insulin secretion and glucose homostasis (Montanya, Tellez, 2009). Changing the balance of beta cell replication and apoptosis alters the length of beta cell cycle which contributes to the islet size and insulin release. Decreasing apoptosis results in the enhancement of beta cell viability and increase in insulin production.

Intrinsic and extrinsic pathways are considered as two general routes for the activation of apoptosis. The former is activated by stress factors including growth factor deprivation, cell cycle disturbance, and DNA damage, which lead to mitochondrial release of cytochrome $c$ and subsequent stimulation of caspase-9. The latter begins with cell death receptors and the associated activation of caspase-8. Finally, both pathways stimulate effector caspases $(3,6$, and 7$)$ which target the substrates that promote DNA fragmentation and cell death (Sharma et al., 2009; Forouzanfar et al., 2013).
It has been well documented that oxidative stress plays an important role in beta cell dysfunction and apoptosis (Yang et al., 2011). Because of poor antioxidant capacity, beta cells are vulnerable to the oxidative stress induced by both T1D insulitis and T2D glucotoxicity (Sharma et al., 2009). Therefore, drugs and phytochemicals that improve glycemia and/or oxidative stress ameliorate or prevent islet lesions. In this regard, protective effect of some phytochemicals on pancreas has been found to be mediated through their antioxidant effects. Zhou et al. (2009) reported that treatment with berberine restored the reduced superoxide dismutase activity and increased lipid peroxidation of pancreas of diabetic animals to the near control level. These antioxidant effects of berberine, therefore, mediate its anti-apoptotic action against beta cell apoptosis in insulin-resistant animal models and against palmitate-induced lipoapoptosis in HIT-T15 insulin producing cells (Gao, Zhao, Li, 2011; Wu, Lu, Dong, 2011). Similarly, the beta cell protective effect of $N$. sativa can be attributed to the antioxidant properties of this plant, which increases superoxide dismutase activity, inhibites lipid peroxidation, and decreases the generation of reactive oxygen species (ROS) in pancreas tissue (Abdelmeguid et al., 2010). Also, reduction of lipid peroxidation in the pancreas of diabetic rats treated with $A$. indica suggests the beneficial potential of this plant in the amelioration of ROS-induced pancreatic islet lesions (Akinola, Caxton-Martins, Dini, 2010). In addition to the direct evidence for pancreas, protective/regenerative effects of the phytochemicals on other tissues may support their beneficial actions on pancreatic structure of diabetic rats. For example, hepatoprotective property of Allicin (Vimal, Devaki, 2004), N. sativa (Al-Ghasham et al., 2008), and A. indica (Oyewole, 2011; Ezz-Din et al., 2011) and nephroprotective action of $N$. sativa (Al-Ghasham et al., 2008) and A. indica (Ezz-Din et al., 2011) have been demonstrated. Also, berberine can promote axonal regeneration in the injured nerves of rats' peripheral nervous system (Han, Heo, Kwon, 2012).

Immunomodulatory action and stimulation of proliferation and differentiation of progenitor cells may be also among the mechanisms involved in beta cell protective/regenerative effects of some phytochemicals (Abiramasundari, Sumalatha, Sreepriya, 2012; Ghazanfari, Hassan, Ebrahimi, 2002).

\section{CONCLUSION}

Destruction of pancreatic islets is the major determinant for the onset of hyperglycemia and development of complications in insulin-dependent diabetic patients. 
Preventing beta cell degeneration, stimulating endogenous regeneration of islets, and islet transplantation will be of essential approaches for T1D management. At present, the limited supply of donor islets prevents tissue transplantation from being used in the patients. Therefore, development of phytochemical products with beta cell regenerative property can be a promising option for the patients who have lost their mass of functional islet cells. Among the hundreds of plants that have been investigated for diabetes, a small fraction has shown the regenerative property, which was described in this paper. For most of these herbs, however, the number of studies supporting their beneficial effects on pancreas is not enough. Only $A$. sativum, $A$. indica, berberine, $C$. sativus, G. sylvestre, J. regia, $M$. charantia, and $N$. sativa had more than one piece of evidence for their regenerative property so that their consumption may decrease insulin dependence on diabetic patients. The exact mechanism responsible for the protective/regenerative effects of phytochemicals on pancreatic islets is yet to be elucidated. However, antioxidant property of phytochemicals may in part mediate their protective action against pancreatic beta cell apoptosis. Regardless of the molecular mechanisms, it seems that patients at the earliest stages of diabetes can be treated with these plants to delay or prevent the full destruction of pancreatic islets. Also, construction of polyherbal compounds through the combination of these phytochemicals may yield more potent regenerative agents for beta cells. Upcoming clinical trials on this topic are particularly warranted.

\section{ACKNOWLEDGMENT}

Salary support was provided by Mashhad University of Medical Sciences. The authors have no other relevant affiliations or financial involvement with any other organization.

\section{REFERENCES}

ABDEL AZIZ, M.T.; El-ASMAR, M.F.; REZQ, A.M.; MAHFOUS, S.M.; WASSEF, M.A.; FOUAD, H.H.; AHMED, H.H.; TAHA, F.M. The effect of a novel curcumin derivative on pancreatic islet regeneration in experimental type-1 diabetes in rats (long term study). Diabetol. Metab. Syndr., v.5, p.75, 2013.

ABDELMEGUID, N.E.; FAKHOURY, R.; KAMAL, S.M.; AL WAFAI, R.J. Effects of Nigella sativa and thymoquinone on biochemical and subcellular changes in pancreatic $\beta$-cells of streptozotocin-induced diabetic rats. J. Diabetes, v.2, p.256-266, 2010.
ABDOLLAHI, M.; ZUKI, A.B.; GOH, Y.M.; REZAEIZADEH, A.; NOORDIN, M.M. Effects of Momordica charantia on pancreatic histopathological changes associated with streptozotocin-induced diabetes in neonatal rats. Histol. Histopathol., v.26, p.13-21, 2011.

ABIRAMASUNDARI, G.; SUMALATHA, K.R.; SREEPRIYA, M. Effects of Tinospora cordifolia (Menispermaceae) on the proliferation, osteogenic differentiation and mineralization of osteoblast model systems in vitro. J. Ethnopharmacol., v.141, p.474-480, 2012.

ADEWOLE, S.O.; CAXTON-MARTINS, E.A. Morphological changes and hypoglycemic effects of Annona Muricata Linn. (Annonaceae) leaf aqueous extract on pancreatic B-Cells of streptozotocin-treated diabetic rats. Afr. J. Biomed. Res., v. 9, p.173-187, 2006.

ADEYEMI, D.O.; KOMOLAFE, O.A.; ADEWOLE, S.O.; OBUOTOR, E.M.; ADENOWO, T.K. Effects of Annona Muricata (Linn) on the morphology of pancreatic islet cells of experimentally-induced diabetic Wistar rats. Internet $J$. Altern. Med., v.5, 2008.

AFSHARI, J.T.; HAJZADEH, M.A.; GHORBANI, A.; PARSAIE, H. Ethanolic extract of Allium sativum has antiproliferative effect on Hep2 and L929 cell lines. Pharmacogn. Mag., v.2, p.29-31, 2006

AHMED, I.; ADEGHATE, E.; SHARMA, A.K.; PALLOT, D.J; SINGH, J. Effects of Momordica charantia fruit juice on islet morphology in the pancreas of the streptozotocindiabetic rat. Diabetes Res. Clin. Pract., v.40, p.145-151, 1998.

AHMED, A.B.; RAO, A.S.; RAO, M.V. In vitro callus and in vivo leaf extract of Gymnema sylvestre stimulate $\beta$-cells regeneration and anti-diabetic activity in Wistar rats. Phytomedicine, v.17, p.1033-1039, 2010.

AHMED, M.F.; KAZIM, S.M.; GHORI, S.S.; MEHJABEEN, S.S.; AHMED, S.R.; ALI, S.M.; IBRAHIM, M. Antidiabetic activity of Vinca rosea extracts in alloxan-induced diabetic rats. Int. J. Endocrinol., v.2010, p.841090, 2010.

AKINOLA, O.B.; CAXTON-MARTINS, E.A.; DINI, L. Chronic treatment with ethanolic extract of the leaves of Azadirachta indica ameliorates lesions of pancreatic islets in streptozotocin diabetes. Int. J. Morphol., v.28, p.291302, 2010. 
ALASHKHAM, F.A.; OSMAN, M.T.; ADNAN, A.; BAKAR, N.S. Histopathological and biochemical effects of Allium Sativum oil administration on type 1 diabetic rats. Res. J. Pharm. Biol. Chem. Sci., v. 4, p. 1045-1053, 2013.

ALBAJALI, A.A.; NAGI, A.H.; SHAHZAD, M.; ULLAH, M.I.; HUSSAIN, S. Effect of Allium sativa L. on pancreatic $\beta$. cells in comparison to Nigella sativa L. in streptozotocin induced diabetic rats. J. Med. Plants Res., v. 5, p.57795784, 2011.

ALINEJAD, B.; GHORBANI, A.; SADEGHNIA, H.R. Effects of combinations of curcumin, linalool, rutin, safranal, and thymoquinone on glucose/serum deprivation-induced cell death. Avicenna J. Phytomed., v.3, p. 321-328, 2013.

AL-GHASHAM, A.; ATA, H.S.; EL-DEEP, S.; MEKI, A.R.; SHEHADA, S. Study of protective effect of date and nigella sativa on aflatoxin B1 toxicity. Int. J. Health Sci. (Qassim), v.2, p.26-44, 2008.

ARALELIMATH, V.R.; BHISE, S.B. Anti-diabetic effects of Gymnema sylvester extract on streptozotocin induced diabetic rats and possible $\beta$-cell protective and regenerative evaluations. Dig. J. Nanomater. Biostruct., v.7, p.135-142, 2012.

ARITAJAT, S.; WUTEERAPOL, S.; SAENPHET, K. Antidiabetic effects of Thunbergia laurifolia L. aqueous extract. Southeast Asian J. Trop. Med. Public Health, v.35, p.53-58, 2004.

ASGARY S,; PARKHIDEH S,; SOLHPOUR S,; MADANI H, MAHZOUNI P,; RAHIMI, P. Effect of ethanolic extract of Juglans regia L. on blood sugar in diabetes-induced rats. J. Med. Food, v.11, p.533-538, 2008.

ASHRAF, R.; KHAN, R.A.; ASHRAF, I.; QURESHI, A.A. Effects of Allium sativum (garlic) on systolic and diastolic blood pressure in patients with essential hypertension. Pak. J. Pharm. Sci., v.26, p.859-863, 2013.

ATANGWHO, I.J.; EBONG, P.E.; EYONG, E.U.; ETENG, M.U.; OBI, A.U. Effect of Vernonia amygdalina Del. leaf on kidney function of diabetic rats. Int. J. Pharm., v.3, p.142-148, 2007.
AVOLIO, F.; PFEIFER, A.; COURTNEY, M.; GJERNES, E.; BEN-OTHMAN, N.; VIEIRA, A.; DRUELLE, N.; FAURITE, B.; COLLOMBAT, P. From pancreas morphogenesis to $\beta$-cell regeneration. Curr. Topics Develop. Biol., v.106, p.217-238, 2013.

BASSEY, T.; ELIAKIM-IKECHUKWU, C.; IHENTUGE, C. Effect of ethanolic stem-bark extract of Anacardium occidentale (Cashew) on the histology of the pancreas of diabetic wistar rats. J. Biol. Agricult. Healthcare, v.2, p.2224-3208, 2012.

BENKEBLIA, N. Free-radical scavenging capacity and antioxidant properties of some selected onions (Allium cepa L.) and garlic (Allium sativum L.) extracts. Braz. Arch. Biol. Technol., vol.48, p.753-759, 2005.

BOUWENS, L.; ROOMAN, I. Regulation of pancreatic betacell mass. Physiol. Rev., v.85, p.1255-1270, 2005.

CHAKRAVARTHY, B.K.; GUPTA, S.; GAMBHIR, S.S.; GODE, K.D. Pancreatic beta cell regeneration: a novel antidiabetic mechanism of Pterocarpus marsupium. Indian J. Pharmacol., v.12, p.123-127, 1980.

CHAKRAVARTHY, B.K.; GUPTA, S.; GODE, K.D. Functional beta cell regeneration in the islets of pancreas in alloxan induced diabetic rats by (-)-epicatechin. Life Sci., v.31, p.2693-2697, 1982.

CHANPOO, M.; PETCHPIBOONTAI, H.; PANYARACHUN, B.; ANUPUNPISIT, V. Effect of curcumin in the amelioration of pancreatic islets in streptozotocin-induced diabetic mice. J. Med. Assoc. Thai., v.93, p.s152-s159, 2010.

DAISY, P.; RAYAN, N.A.; RAJATHI, D. Hypoglycemic and other related effects of Elephantopus scaber extracts on alloxan induced diabetic rats. J. Biol. Sci., v.7, p.433-437, 2007.

DARMONOSYAMSUDIN, S.; SIMANJUNTAK, P. The effects of Leucaena leucocephala (lmk) De Wit seeds on blood sugar levels: an experimental study. Int. J. Sci. Res., v.2, p.49-52, 2006.

DAUR, I. Chemical properties of the medicinal herb Kaff Maryam (Anastatica hierochuntica L.) and its relation to folk medicine use. Afr. J. Microbiol. Res., v.6, p.5048-5051, 2012. 
DEHGHANI, F.; MASHHOODY, T.; PANJEHSHAHIN, M. Effect of aqueous extract of walnut septum on blood glucose and pancreatic structure in streptozotocin-induced diabetic mouse. Ir. J. Pharmacol. Ther., v.11, p.10-14, 2012.

DESHPANDE, A.D.; HARRIS-HAYES, M.; SCHOOTMAN, M. Epidemiology of diabetes and diabetes-related complications. Phys. Ther., v.88, p.1254-1264, 2008.

EBONG, P.E.; ATANGWHO, I.J.; EYONG, E.U.; UKWE, C.; OBI, A.U. Pancreatic Beta cell regeneration: a probable parallel mechanism of hypoglycaemic action of Vernonia amygdalina Del and Azadirachta indica. In: INTERNATIONAL NEEM CONFERENCE, 2006, Kunming, China. Available at: $<$ http://neem.tea-nifty.com/ neem/files/14.\%20Prof.Patrick\%20Ebong.pdf > . Accessed on: Jan. 2014.

ELGAZAR, A.F.; REZQ, A.A.; BUKHARI, H.M. Antihyperglycemic effect of saffron extract in alloxan-induced diabetic rats. Eur. J. Biol. Sci., v.5, p.14-22, 2013.

ELIAKIM-IKECHUKWU, C.F.; EDEM, A.A.; WILLIAM, U.; OKORI, S.O.; IHENTUGE, C.J. Phytochemical composition of Cassia alata leaf extract and its effect on the histology of the pancreas of diabetic wistar rats. IOSR. J. Pharm. Biol. Sci., v.5, p.07-13, 2013.

ELIAKIM-IKECHUKWU, C.F.; OBRI, A.I. Histological changes in the pancreas following administration of ethanolic extract of Alchornea cordifolia leaf in alloxaninduced diabetic Wistar rats. Nigerian J. Physiol. Sci., v.24, p.153-155, 2009.

EZZ-DIN, D.; GABRY, M.S.; FARRAG, A.H.; MONEIM, A.E.A. Physiological and histological impact of Azadirachta indica (neem) leaves extract in a rat model of cisplatininduced hepato and nephrotoxicity. J. Med. Plants Res., v.5, p.5499-5506, 2011.

FOROUZANFAR, F.; GOLI, A.A.; ASSADPOUR, E.; GHORBANI, A.; SADEGHNIA, H.R. Protective effect of Punica granatum L. against serum/glucose deprivationinduced PC12 cells injury. Evid. Based Complement. Alternat. Med., v.2013, p.716-730, 2013.

GAO, N.; ZHAO, T.Y.; LI, X.J. The protective effect of berberine on $\beta$-cell lipoapoptosis. J. Endocrinol. Invest., v.34, p.124-130, 2011.
GHAZANFARI, T.; HASSAN, Z.M.; EBRAHIMI, M. Immunomodulatory activity of a protein isolated from garlic extract on delayed type hypersensitivity. Int. Immunopharmacol., v.2, p.1541-1549, 2002.

GHORBANI, A. Best herbs for managing diabetes: A review of clinical studies. Braz. J. Pharm. Sci., v.49, p.413-422, 2013a.

GHORBANI, A. Phytotherapy for diabetic dyslipidemia: evidence from clinical trials. Clin. Lipidol., v.8, p.311-319, 2013 b.

GHORBANI, A.; VAREDI, M.; HADJZADEH, M.R.; OMRANI, G.H. Type-1 diabetes induces depot-specific alterations in adipocyte diameter and mass of adipose tissues in the rat. Exp. Clin. Endocrinol. Diabetes, v.118, p.442-448, 2010.

GHORBANI, A.; OMRANI, G.H.; HADJZADEH, M.R.; VAREDI, M. Proinsulin C-peptide inhibits lipolysis in diabetic rat adipose tissue through phosphodiestrase-3B enzyme. Horm. Metab. Res., v.45, p.221-225, 2013.

GIRIJA, K.; LAKSHMAN, K.; UDAYA, C.; SABHYA, S.G.; DIVYA, T. Anti-diabetic and anti-cholesterolemic activity of methanol extracts of three species of Amaranthus. Asian Pac. J. Trop. Biomed., v.2, p.133-138, 2011.

GOLALIPOUR, M.J.; GHAFARI, S.; KOURI, V.; KESTKAR, A.A. Proliferation of the $\beta$-Cells of pancreas in diabetic rats treated with Urtica Dioica. Int. J. Morphol., v.28, p.399404, 2010.

HAFIZUR, R.M.; KABIR, N.; CHISHTI, S. Modulation of pancreatic $\beta$-cells in neonatally streptozotocin-induced type 2 diabetic rats by the ethanolic extract of Momordica charantia fruit pulp. Nat. Prod. Res., v.25, p.353-367, 2011.

HAJZADEH, M.R.; TAVAKOLAFSHARI, J.; GHORBANI, A.; SHAKERI, M.T. The effects of aqueous extract of garlic (Allium sativum L.) on laryngeal cancer cells (Hep-2) and L929 cells in vitro. J. Med. Plants, v.5, p.41-48, 2006.

HAN, A.M.; HEO, H.; KWON, Y.K. Berberine promotes axonal regeneration in injured nerves of the peripheral nervous system. J. Med. Food, v.15, p.413-417, 2012. 
JELODAR, G.A.; MALEKI, M.; MOTADAYEN, M.H.; SIRUS, S. Effect of fenugreek, onion and garlic on blood glucose and histopathology of pancreas of alloxan-induced diabetic rats. Indian. J. Med. Sci., v.59, p.64-69, 2005.

JELODAR, G.; MOHSEN, M.; SHAHRAM, S. Effect of walnut leaf, coriander and pomegranate on blood glucose and histopathology of pancreas of alloxan induced diabetic rats. Afr. J. Trad. CAM., v.4, p.299-305, 2007.

JAVIDANPOUR, S.; TABTABAEI, S.R.F.; SIAHPOOSH, A.; MOROVATI, H.; SHAHRIARI, A. Comparison of the effects of fresh leaf and peel extracts of walnut (Juglans regia $L$.) on blood glucose and $\beta$-cells of streptozotocininduced diabetic rats. Vet. Res. Forum, v.3, p.251-255, 2012.

KAMYAB, H.; HEJRATI, S.; KHANAVI, M.; MALIHI, F., MOHAMMADIRAD, A.; BAEERI, M. Hepatic mechanisms of the walnut antidiabetic effect in mice. Cent. Eur. J. Biol., v.5, p.304-309, 2010.

KANTER, M. Protective effects of thymoquinone on $\beta$-cell damage in streptozotocin-induced diabetic rats. T.A.D., v.7, p.64-70, 2009.

KANTER, M.; COSKUN, O.; KORKMAZ, A.; OTER, S. Effects of Nigella sativa on oxidative stress and beta-cell damage in streptozotocin-induced diabetic rats. Anat. Rec. A Discov. Mol. Cell Evol. Biol., v.279, p.685-691, 2004.

KANTER, M.; MERAL, I.; YENER, Z.; OZBEK, H.; DEMIR, H. Partial regeneration/proliferation of the beta-cells in the islets of Langerhans by Nigella sativa L. in streptozotocininduced diabetic rats. Tohoku J. Exp. Med., v.201, p.213219, 2003.

KAVALALI, G.; TUNCEL, H.; GOKSEL, S.; HATEMI, H.H. Hypoglycemic activity of Urtica pilulifera in streptozotocindiabetic rats. J. Ethnopharmacol., v.84, p.241-245, 2003.

KIANBAKHT, S.; HAJIAGHAEE, R. Anti-hyperglycemic effects of saffron and its active constituents, crocin and safranal, in alloxan-induced diabetic rats. J. Med. Plants, v.10, p.82-89, 2011.

KOCHHAR, A.; SHARMA, N.; SCHDEVA, R. Effect of supplementation of tulsi (Ocimum sanctum) and neem (Azadirachta indica) leaf powder on diabetic symptoms, anthropometric parameters and blood pressure of non insulin dependent male diabetics. Etno-Med., v.3, p.5-9, 2009.
KOTI, B.C.; BIRADAR, S.M.; KARADI, R.V.; TARANALLI, A.D.; BENADE, V.S. Effect of Bauhinia variegata bark extract on blood glucose level in normal and alloxanised diabetic rats. J. Nat. Remed., v.9, p.27-34, 2009.

KULKARNI, C.P.; BODHANKAR, S.L.; GHULE, A.E.; MOHAN, V.; THAKURDESAI, P.A. Antidiabetic activity of Trigonella foenum-graecum L. seed extract (IND01) in neonatal streptozotocin-induced (N-STZ) rats. Diabetologia Croat., v.41, n.1, p.29-36, 2012.

KUMARI, D.J. Hypoglycaemic effect of Moringa oleifera and Azadirachta indica in type 2 diabetes mellitus. Bioscan, v.5, p.211-214, 2010.

LORENZATI, B.; ZUCCO, C.; MIGLETTA, S.; LAMBERTI, F.; BRUNO, G. Oral hypoglycemic drugs: pathophysiological basis of their mechanism of action. Pharmaceuticals, v.3, p.3005-3020, 2010.

MANIYAR, Y.A.; UMAMAGESWARI, M.S.; KARTHIKEYAN, T.M. Evaluation of antihyperglycemic activity of aqueous extract of leaves of Solanum nigrum in alloxan induced diabetic rats. I.J.P.B.S., v.2, p.312-319, 2012.

MEIER, J.J.; LIN, J.C.; BUTLER, A.E.; GALASSO, R.; MARTINEZ, D.S.; BUTLER, P.C. Direct evidence of attempted beta cell regeneration in an 89-year-old patient with recent-onset type 1 diabetes. Diabetologia, v. 49, p. 1838-1844, 2006.

MIR, S.H.; DARZI, M.; MIR, M.S. Efficacy of Abroma augusta on biochemical and histomorphological features of alloxaninduced diabetic rabbits. Iran. J. Path., v.8, p.153-158, 2013.

MOHAJERI, D.; MOUSAVI, G.; DOUSTAR, Y. Antihyperglycemic and pancreas-protective effects of Crocus sativus L. (saffron) stigma ethanolic extract on rats with alloxan-induced diabetes. J. Biol. Sci., v.9, p. 302-310, 2009.

MOHAMMADI, J.; PRAKASH, R.N. Evaluation of hypoglycemic effect of Morus alba in an animal model. Indian. J. Pharmacol., v.40, p.15-18, 2008.

MONTANYA, E.; TÉLLEZ, N. Pancreatic remodeling: beta-cell apoptosis, proliferation and neogenesis, and the measurement of beta-cell mass and of individual beta-cell size. Methods Mol. Biol., v.560, p.137-158, 2009. 
OSMAN, M.; ADNAN, A.; BAKAR, N.S.; ALASHKHAM, F. Allicin has significant effect on autoimmune anti-islet cell antibodies in type 1 diabetic rats. Pol. J. Pathol., v.63, p.248-254, 2012.

OYEWOLE, O.I. Ameliorating effect of methanolic leaf extract of Azadirachta indica (neem) on arsenic-induced oxidative damage in rat liver. Int. J. Toxicol. Appl. Pharmacol., v.1, p.25-28, 2011.

PARK, S.Y.; KIM, H.S.; CHO, E.K.; KWON, B.Y.; PHARK, S.; HWANG, K.W.; SUL, D. Curcumin protected PC12 cells against beta-amyloid-induced toxicity through the inhibition of oxidative damage and tau hyperphosphorylation. Food Chem. Toxicol., v.46, p.2881-2887, 2008.

QOMARIYAH, N.; SARTO, M.; PRATIWI, R. Antidiabetic effects of a decoction of leaves of Sansevieria trifasciata in alloxan- induced diabetic white rats. ITB J. Sci., v.44 p.308-316, 2012.

RAHMY, T.R.; El-RIDI, M.R. Action of Anastatica hierochuntica plant extract on islets of Langerhans in normal and diabetic rats. Egypt. J.Biol., v. 4, p. 87-94, 2002.

RAJALAKSHMI, M.; ELIZA, J.; PRIYA, C.E.; NIRMALA, A.; DAISY, P. Anti-diabetic properties of Tinospora cordifolia stem extracts on streptozotocin- induced diabetic rats. Afr. J. Pharm. Pharmacol., v.3, p.171-180, 2009.

SADEGHNIA, H.R.; KAMKAR, M.; ASSADPOUR, E.; BOROUSHAKI, M.T.; GHORBANI, A. Protective effect of safranal, a constituent of Crocus sativus, on quinolinic acid-induced oxidative damage in rat hippocampus. Ir. J. Basic Med. Sci., v.16, p.73-82, 2013.

SAMARGHANDIAN, S.; BORJI, A.; DELKHOSH, M.B.; SAMINI, F. Safranal treatment improves hyperglycemia, hyperlipidemia and oxidative stress in streptozotocininduced diabetic rats. J. Pharm. Pharm. Sci., v.16, p.352$362,2013$.

SANKARANARAYANAN, C.; PARI, L. Thymoquinone ameliorates chemical induced oxidative stress and $\beta$-cell damage in experimental hyperglycemic rats. Chem. Biol. Interact., v.25, p.148-154, 2011.
SELVAN, V.T.; MANIKANDAN, L.; SENTIL, G.P.; SURESH, R.; KAKOTI, B.B.; GOMATHI, P.; KUMAR, D.A.; SAHA, P.; GUPTA, M.; MAZUMDER, U.K. Antidiabetic and antioxidant effect of methanol extract of artanema sesamoides in streptozocin-induced diabetic rats. Int. J. Appl. Res. Nat. Prod., v.1, p. 25-33, 2008.

SHABAN, F.; Al-AZZAWIE, H.F.; MOHAMMED, A.S. Effect of alcoholic Anastatica hierochuntica extract on some biochemical and histological parameters in alloxan induced diabetic rats. Iraqi J. Sci., v.52, p.445-455, 2011.

SHAFIEE-NICK, R.; PARIZADEH, S.M.R.; ZOKAEI, N.; GHORBANI, A. Effect of hydro-alcoholic extract of Vaccinium arctostaphylos on insulin release from ratisolated langerhans islets. Koomesh, v.12, p.447-452, 2011.

SHAFIEE-NICK, R.; PARIZADEH, S.M.R.; ZOKAEI, N.; GHORBANI, A. Effects of Ganoderma lucidum hydroalcoholic extract on insulin release in rat-isolated pancreatic islets. Avicenna J. Phytomed., v.2, p.206-211, $2012^{\mathrm{a}}$.

SHAFIEE-NICK, R.; GHORBANI, A.; VAFAEE, F.; RAKHSHANDEH, H. Chronic administration of a combination of six herbs inhibits the progression of hyperglycemia and decreases serum lipids and aspartate amino transferase activity in diabetic rats. Adv. Pharmacol. Sci., v.2012, p.789-796, 2012 .

SHANMUGASUNDARAM, E.R.B.; RAJESWARI, G .; B A S K A R A N, K .; KUMAR, B .R.R .; SHANMUGASUNDARAM, K.R.; AHMATH, B.K. Use of Gymnema sylvestre leaf extract in the control of blood glucose in insulin-dependent diabetes mellitus. $J$. Ethnopharmacol., v.30, p.281-294, 1990.

SHARMA, V.; KALIM, S.; SRIVASTAVA, M.K.; NANDA, S.; MISHRA, S. Oxidative stress and coxsackie virus infections as mediators of beta cell damage: A review. Sci. Res. Essay, v.4, p.42-58, 2009.

SINGH, N.; GUPTA, M. Effects of ethanolic extract of Syzygium cumini (Linn) seed powder on pancreatic islets of alloxan diabetic rats. Indian J. Exp. Biol., v.45, p.861-867, 2007a.

SINGH, N.; GUPTA, M. Regeneration of beta cells in islets of Langerhans of pancreas of alloxan diabetic rats by acetone extract of Momordica charantia (Linn.) (bitter gourd) fruits. Indian J. Exp. Biol., v.45, p.1055-1062, 2007 b. 
SINGH, N.; GUPTA, M.; SIROHI, P.; VARSH, A. Effects of alcoholic extract of Momordica charantia (Linn.) whole fruit powder on the pancreatic islets of alloxan diabetic albino rats. J. Environ. Biol., v.29, p.101-106, 2008.

SOLTANI BAND, K.; FARKHAD, N.K.; FAROKHI, F.; TOGMECHI, A. Effects of hydro-alcoholic extract of Prangos ferulacea (L.) Lindle on histopathology of pancreas and diabetes treatment in STZ- induced diabetic rats. Avicenna J. Phytomed., v. 2, p.31-38, 2011.

SUNDAY, J.J.; SPENCER, C.O.; KINGSLEY, O.; AKINTOLA, A.A.; BINYELUM, N.; FAVOUR, A.O. Possible revival of atrophied islet cells of the pancreas by Vernonia amygdalina in alloxan induced diabetic rats. J. Appl. Pharm. Sci., v. 2, p.127-131, 2012.

TANG, L.Q.; WEI, W.; CHEN, L.M.; LIU, S. Effects of berberine on diabetes induced by alloxan and a high-fat/ high-cholesterol diet in rats. J. Ethnopharmacol., v.108, p.109-115, 2006.

TZOULAKI, I.; MOLOKHIA, M.; CURCIN, V.; LITTLE, M.P.; MILLETT, C.J.; NG, A.; HUGHES, R.I.; KHUNTI, K.; WILKINS, M.R.; MAJEED, A.; ELLIOTT, P. Risk of cardiovascular disease and all cause mortality among patients with type 2 diabetes prescribed oral antidiabetes drugs: retrospective cohort study using UK general practice research database. Brit. Med. J., v.339, p.b4731, 2009.

VERMA, L.; KHATRI, A.; KAUSHIK, B.; PATIL, K.; PAWAR, R.S. Antidiabetic activity of Cassia occidentalis (Linn) in normal and alloxan-induced diabetic rats. Indian $J$. Pharmacol., v.42, p.224-228, 2010.

VERMA, P.R.; ITANKAR, P.R.; ARORA, S.K. Evaluation of antidiabetic anti-hyperlipidemic and pancreatic regeneration, potential of aerial parts of Clitoria ternatea. Rev. Bras. Farmacogn., v.23, p.819-829, 2013.

VIMAL, V.; DEVAKI, T. Hepatoprotective effect of allicin on tissue defense system in galactosamine/endotoxin challenged rats. J. Ethnopharmacol., v.90, p.151-154, 2004.
WANG, H.L.; LI, C.Y.; ZHANG, B.; LIU, Y.D.; LU, B.M.; SHI, Z.; AN, N.; ZHAO, L.K.; ZHANG, J.J.; BAO, J.K.; WANG, Y. Mangiferin facilitates islet regeneration and $\beta$-cell proliferation through upregulation of cell cycle and $\beta$-cell regeneration regulators. Int. J. Mol. Sci., v.15, p.90169035, 2014.

WORLD HEALTH ORGANIZATION. WHO. Diabetes. Fact Sheet No. 312. Geneva, 2015. Available at: <http://www. who.int/mediacentre/factsheets/fs312/en/>. Accessed on: Jan, 2014.

WU, S.; LU, F.E.; DONG, H. Effects of berberine on the pancreatic beta cell apoptosis in rats with insulin resistance. Chin. J. Integr. Tradit. West. Med., v.31, p.1383-1388, 2011.

YANG, H.; JIN, X.; LAM, C.W.; YAN, S.K. Oxidative stress and diabetes mellitus. Clin. Chem. Lab. Med., v.49, p.17731782,2011

YAZDANPARAST, R.; ESMAEILI, M.A.; ASHRAFI, H.J. Teucrium polium extract effects pancreatic function of streptozotocin diabetic rats: a histopathological examination. Ir. Biomed. J., v.9, p.81-85, 2005.

YE, M.; FU, S.; PI, R.; HE, F. Neuropharmacological and pharmacokinetic properties of berberine: a review of recent research. J. Pharm. Pharmacol.,v.61, p.831-837, 2009.

YIN, J.; XING, H.; YE, J. Efficacy of berberine in patients with type 2 diabetes mellitus. Metabolism, v.57, p.712-717. 2008.

ZHOU, J.; ZHOU, S.; TANG, J.; ZHANG, K.; GUANG, L.; HUANG, Y.; XU, Y.; YING, Y.; ZHANG, L.; LI, D. Protective effect of berberine on beta cells in streptozotocinand high-carbohydrate/high-fat diet-induced diabetic rats. Eur. J. Pharmacol., v.606, p.262-268, 2009.

Received for publication on $30^{\text {th }}$ January 2014 Accepted for publication on $28^{\text {th }}$ January 2015 